\title{
JOVENS, COTIDIANO E A CONSTRUÇÃO DE MUNDOS MIDIÁTICOS ${ }^{1}$
}

\section{YOUNG, DAILY LIVES AND CONSTRUCTION OF MEDIATIC WORLDS}

\author{
Benedito Dielcio MOREIRA ${ }^{2}$
}

Resumo: Os jovens constroem e reconstroem cotidianamente mundos a partir de suas relações com o universo midiático. Independentemente, porém, do mundo privado criado por cada um, a questão está no fio condutor que orienta esse processo. Nas relações dos jovens com as mídias e com as tecnologias de informação, mundos são cotidianamente construídos e reconstruídos a partir de versões criadas pelos atores midiáticos, cada vez mais sem a participação dos adultos, familiares e professores, a quem a sociedade delega a responsabilidade para educar seus filhos. Diante da vastidão de informações, eles realizam escolhas, as quais julgam ter relação com os mundos que habitam. Estas reflexões resultam de um estudo realizado com 110 jovens, de quatro tipos diferentes de escolas.

Palavras Chaves: Jovens; Mídias; Realidade; Educação .

\begin{abstract}
The young build and rebuild worlds everyday from their relations with the mediatic universe. Regardless, however, of the private world created by each one, the question is in the thread that guides this process. In the relations of young with the media and information technologies, worlds are daily constructed and reconstructed from versions created by mediatic actors, increasingly without the participation of adults, relatives and teachers, to whom society entrusts the responsibility of educating their children. Given the vast wealth of information, they make choices, which they believe to be related to the worlds they inhabit. These reflections are the result of a study of 110 young people from four different schools.

\footnotetext{
${ }^{1}$ Este texto contém novas discussões para semelhante temática apresentada na Universidade Federal do Paraná, em 2009, no II Seminário Internacional sobre Cultura, Imaginário e Memória da América Latina.

2 Jornalista, professor do Departamento de Comunicação Social da Universidade Federal de Mato Grosso - UFMT. Mestre em Ciências da Comunicação pela Universidade de São Paulo - USP e doutor em Educação pela Universität Siegen, Alemanha, coordena o Grupo de Pesquisa "Comunicação, Infância e Juventude”. Desenvolve pesquisas em Comunicação e Cultura Científica, Recepção e Educomunicação. É coordenador operacional do DINTER em Comunicação, UFMG/UFMT.
} 


\section{míDiA eCOti DiAno}

\section{PPGMC}

Keywords: Youth; Media; Reality; Education.

\section{Introdução}

Este trabalho discute a relação do jovem, com idade entre 14 e 16 anos, com o universo midiático ${ }^{3}$, os mundos que ele constrói e quem participa com ele neste processo: amigos, familiares, atores midiáticos e professores. Trata-se de parte de um estudo realizado com 110 jovens de ambos os sexos, matriculados no primeiro ano do Ensino Médio, em quatro diferentes escolas de três cidades do país ${ }^{4}$. O estudo completo compreendeu a aplicação de um questionário com perguntas abertas e fechadas sobre hábitos de consumo de mídias, discussão com todos os respondentes de cada escola sobre as respostas recorrentes e divergentes do questionário e o aprofundamento dos temas mais polêmicos com um grupo de oito alunos em cada escola. Foram também ouvidos professores das respectivas turmas, diretores e coordenadores pedagógicos das quatro escolas.

Além da adesão de professores, pais e alunos, a escolha das escolas obedeceu a dois critérios centrais. Primeiro, situar-se na cidade São Paulo ou na região de influência da grande metrópole. Segundo, atender aos grupos sociais de consumo segundo a classificação do Critério Brasil ${ }^{5}$. A decisão pelo Critério Brasil para identificar os diferentes grupos de alunos se deve ao fato de que a escolha da escola, se privada, na maioria das vezes tem relação direta com o poder de compra dos pais. Observou-se também, ao longo de toda a pesquisa, que os quatro grupos são recorrentes em algumas

\footnotetext{
${ }^{3}$ Por relação com o universo midiático considero tanto o contato dos jovens com todos os artefatos tecnológicos de armazenagem e transmissão de informações, quanto com os conteúdos. Assim, quando falo em mídia, meios de comunicação e tecnologias de informação, conforme conceito atribuído por Castells (2001, p.49), me refiro a um conjunto de meios eletrônicos e impressos que cumprem uma função mediadora da realidade.

${ }^{4}$ Estudo completo foi defendido como tese de doutorado, na Alemanha. Texto disponível no seguinte endereço: http://dokumentix.ub.uni-siegen.de/opus/volltexte/2008/375/

${ }^{5}$ A versão do Critério Brasil utilizada no estudo é a de 2008. Disponível em http://www.abep.org/new/.
} 


\section{míDiA eCOti DiAno}

\section{PPGMC}

questões relacionadas ao consumo midiático e não se diferenciam apenas na capacidade de consumo de suas famílias, mas, sobretudo, na interpretação do conteúdo das mídias e na expectativa que cada grupo tem da formação escolar.

Assim, as escolas e seus públicos estão articulados neste texto em quatro categorias de análise: $\mathrm{Na}$ escola 1 , os alunos e alunas pertencem majoritariamente ao grupo de consumo $\mathrm{C} 1$ e $\mathrm{C} 2^{6}$. São os trabalhadores que estudam. Para eles, a Universidade não existe enquanto perspectiva de estudo. Na escola 2 estão os estudantes que trabalham, pertencentes aos grupos de consumo $\mathrm{C} 1$ e $\mathrm{B} 2^{7}$, principalmente. Para eles, a Universidade se apresenta como uma possibilidade. Na escola 3 estão os estudantes que precisam estudar, pertencentes em sua maioria aos grupos de consumo B2, B1 ${ }^{8}$, para os quais a Universidade, especialmente a pública, é a melhor opção. Finalmente, na escola 4, estão os estudantes que só estudam. Formados majoritariamente pelo grupo de Consumo $\mathrm{A}^{9}$, para estes jovens a universidade, pública ou privada, é um caminho natural.

Este texto tem como ponto central discutir as versões de mundo reconstruídas pelos alunos e alunas das quatro escolas, assim como debater a participação das mídias e das tecnologias de informação nesse processo. Partimos da constatação de que os meios de comunicação constroem e disseminam as suas versões particulares de mundo e encontram no campo da recepção jovens que permanecem mais tempo envolvidos com os diferentes meios (de segunda a domingo, em média cinco horas por dia) do que o tempo dedicado à escola e às conversas com familiares. Após a discussão teórica sobre as mídias, a formação de realidades e a construção de mundos, alguns resultados

\footnotetext{
${ }^{6}$ Este grupo tem renda média familiar de $\mathrm{R} \$ 933,00$ (C2) e $\mathrm{R} \$ 1.391,00$ (C1).

${ }^{7} \mathrm{Na}$ versão 2008 do Critério Brasil, este grupo tem renda média familiar de R\$1.391,00 (C1) e R\$ $2.327,00$ (B2).

${ }^{8} \mathrm{Na}$ escola três, a renda média familiar dos alunos é de $\mathrm{R} \$ \mathrm{R} \$ 2.327,00$ (B2) e $\mathrm{R} \$ 4.558,00$ (B1).

${ }^{9} \mathrm{O}$ grupo de alunos identificados como pertencentes ao grupo A tem renda familiar superior a $\mathrm{R} \$$ $8.099,00$.
} 


\section{míDiA eCOti DiAno}

empíricos são apresentados e identificados conforme as quatro categorias acima assinaladas.

\section{Construtores de Mundos}

Os jovens de hoje se deparam com um sistema midiático que insere a informação jornalística em praticamente todos os fluxos midiáticos que frequentam. A notícia, tal como hoje é veiculada, é um produto urbanizado, feito sob medida para atingir a todas as pessoas, independente do grau de escolaridade ou mesmo do nível de desenvolvimento de um país (MEDINA, 1988). Assim como as tecnologias disponíveis no mercado realimentam o mito da igualdade social, o produto notícia, colocado à venda, alimenta o mito de que a notícia é o espelho da realidade. Em outros termos, os centros emissores de informação, ou os conectores, tal como os denomina Castells (2001), realizam filtros, escolhas, decidem o que é noticiável, o que é entretenimento. Em nome do desejo manifesto pela audiência, geralmente identificado por meio de pesquisas de sondagem de opinião, são produzidas e geradas informações e escolhidas as que são veiculáveis, segundo a orientação editorial de cada meio. Já na recepção, quando aceitamos as tecnologias e as informações, disponibilizadas em diferentes formatos, assim o fazemos porque julgamos serem elas relevantes: trata-se de uma relevância que tem vínculos estreitos com a nossa cotidianidade.

Este processo, portanto, não é passivo. A relevância percebida gera leituras, que são sempre dialógicas, no pensar de Bakhtin (2003 e 2004). Do diálogo com a informação decorre necessariamente a desconstrução da mensagem recebida e a imediata reconstrução de uma nova versão. A considerar, inclusive, que os meios de comunicação e as novas tecnologias de informação têm decisiva importância na produção e na transmissão de informações, e que este processo é sempre a edição de 


\section{míiA eCOti DiAno}

uma versão da realidade, então do contato com a informação surgirá sempre uma reedição, outra versão, a versão compartilhada com os grupos sociais.

Os sistemas de informação midiáticos têm importância vital nas realidades que edificamos em nosso cotidiano. O 'real', postula Certeau (1994, p.289), "é aquilo que, em cada lugar, a referência a um outro faz acreditar". Ou seja, os múltiplos "relatos", com a pretensão de se tornar parte da realidade, se multiplicam em "citações" e "recitação", buscam tornar a crença no real fundamentado naquilo que é visível. Conforme Berger e Luckmann (2002), o real é aquilo que se conhece como realidade, ou seja, o que é real é um tipo de questionamento inexistente na vida cotidiana, salvo se a pessoa estiver diante de um problema que a obrigue a repensar o que ela julgava certo.

Berger e Luckmann (2002, p.38) argumentam que não há apenas uma, mas múltiplas realidades que são experimentadas, construídas pela e na interpretação. Destas, porém, uma é vital: "É a realidade da vida cotidiana. Sua posição privilegiada autoriza a dar-lhe a designação de realidade predominante". A realidade do cotidiano, para Schütz e Luckmann (1975) traz em sua estrutura de base a realidade da vida no mundo: é o cotidiano do mundo vivido. A realidade do cotidiano é a realidade imediata. Está fincada no aqui, enquanto corpo, e no agora enquanto tempo. Assim, o tempo presente é a presença do indivíduo no cotidiano, é a comprovação de que a realidade existe (BERGER e LUCKMANN, 2002).

O tempo presente tem, portanto, importância vital tanto para as mídias centradas na informação quanto na existência cotidiana. O pensamento acerca do nosso tempo presente tem, como tem o mar para o olhar inaugural de uma criança, a beleza e a vastidão do novo: "Pai, me ajuda a olhar!"10. Portanto, postar a realidade diante dos

\footnotetext{
${ }^{10}$ Para explicar a função da arte, conta Eduardo Galeano (1995, p.15), um pai levou o seu filho para conhecer o mar. Diante do inimaginável, o filho balbuciou: "pai, me ajuda a olhar".
} 


\section{míDiA eCOti DiAno}

olhos e olhar, e desta conjugação extrair um pensamento, um conhecimento que a traduza, é uma tarefa descomunal, que não se faz sem a ajuda de outros olhares: suporte que hoje os jovens obtêm, principalmente, do sistema midiático. Pelo sistema midiático tudo se converte em um eterno presente: "O prazer que obtemos com a representação do presente deve-se não apenas à beleza de que ele pode estar revestido, mas também à sua qualidade essencial de presente" (BAUDELAIRE, 1996, p.8). O tempo presente é a qualidade essencial do universo midiático. Com toda a sua magnitude, fascinação e encantamento, os meios constroem, a todo o momento, estados simbólicos e singulares de presente. Três elementos são, portanto, vitais na composição das forças simbólicas deste processo de construção e reconstrução: o social, a história e a cultura. Neste sentido, o presente está submisso às forças que o compõem e nele inferem, nele evocam o que sempre foram partes de sua composição: a correlação de forças, o tempo e o lugar.

É nesta arena, na qual coexistem o passado e o futuro atuando decisivamente na composição do presente, que a correlação de forças entre os sujeitos, inclusive os midiáticos, se constitui. No desenvolvimento de uma pessoa são apreendidos signos que se transformam em representações mentais da realidade. "São as marcas internas do exterior”, diz Tomasello (2003). É a partir da operacionalização desse sistema que o homem intervém, constrói o seu mundo. O sistema simbólico de interação surge e é constituído na cultura, segundo Tomasello. Há, portanto, a ação externa sobre o indivíduo, "mas o sentido dessa realidade depende das necessidades daquele, de sua ideologia, de suas aspirações, conformadas em seu próprio desenvolvimento histórico" (GONZÁLEZ REY, 2003, p.94).

Assim, o que se mostra, o que se constrói, se dá na conexão entre a realidade e a linguagem, entre o mundo e a palavra, no dizer de Freire (2002). Ao utilizar um acervo pessoal para interpretar a realidade realiza-se imediatamente uma intervenção sobre ela (ADORNO, 2003). Os alunos e as alunas das quatro escolas com os quais trabalhei 


\section{míDiA eCOti DiAno}

neste estudo estão em situações sociais diferenciadas, herdaram habitus distintos, estão em contextos históricos e sociais também distintos. As interpretações que eles dão aos diferentes mundos que os circundam são referenciadas, como pensa Schütz (2003), em acervos de experiências, acumuladas pelos que antecederam, pela própria experiência e pelo que nos é transmitido por quem está ao nosso lado. É o conhecimento à mão (SCHÜTZ, 2003, p.198). Nesse sentido, a formação de nossos juízos decorre da complexidade e da singularidade de nossas experiências, aprendizado e interações.

As quatro escolas visitadas disponibilizam aos alunos contextos distintos. A escola dos trabalhadores que estudam é noturna. Por conta dos constantes conflitos entre grupos, as salas de aula, as salas de direção e de secretarias e os pátios estão isolados por grades. A escola não dispõe de equipamentos de apoio à aprendizagem e um roubo deixou o laboratório de informática sem computadores. Já a escola dos estudantes que trabalham, ou seja, daqueles que veem a universidade como uma possibilidade, é também pública, noturna, tem alguns instrumentos de apoio pedagógicos, tais como TV e aparelho de DVD, e não tem um laboratório de informática completamente montado. Por sua vez, a escola frequentada por alunos que lutam para ingressar em uma universidade, especialmente pública, é matutina, privada, vinculada a um sistema de ensino, e disponibiliza aos seus alunos todas as ferramentas tecnológicas de apoio ao ensino e à aprendizagem. A escola dos alunos que têm como certo seu ingresso em alguma universidade é também privada e atende aos alunos nos períodos matutino e vespertino. Ali, o aluno tem todas as tecnologias de comunicação e informação disponíveis e atendimento personalizado.

As quatro escolas constituem, portanto, mundos distintos. E os mundos que os jovens destas escolas edificam não surgem do nada, uma vez que, recorrendo a Husserl (2006, 1992) e Schütz (2003), a geração de entendimentos é delineada por um horizonte presente, assentado em um passado e esboçado em direção ao futuro. De outro modo, e 


\section{míDiA eCOti DiAno}

\section{PPGMC}

me beneficiando da análise que Capalbo (1998, p.54) faz da fenomenologia de Schütz, os jovens (mas não somente eles) estão envolvidos em um "sistema de relações" que os mantém atados aos seus projetos. Estes não estão isolados, mas orquestrados em um "sistema de interesses". É aqui, neste "sistema de interesses", que as mídias ocupam preponderante função: tanto construindo seus mundos, como fornecendo material simbólico para a construção de mundos desejados.

Para Goodman (1995, p.41), não se questiona a existência de muitas versões de mundo. Importa "que muitas versões diferentes de mundo têm importância e interesses autônomos, sem qualquer exigência ou presunção de redutibilidade a uma base única". Para este autor (p.42), a existência de uma única versão, ou a redução das versões em uma única versão, exigiria uma verdade única sobre o mundo: "Exigir redutibilidade exclusiva e completa à física ou a uma outra versão qualquer é abrir mão de quase todas as outras versões". Em outros termos, as diferentes versões de uma mesma coisa indicam que a mesma coisa não é de fato a mesma, porque a realidade não existe independente das versões que dela são traçadas. Aqui, a preocupação central de Goodman (1995) não é saber como os mundos particulares são feitos a partir dos outros mundos percebidos, mas a relação que há entre os diferentes mundos. Assim, como um sistema de símbolos não cai do "espaço sideral", é decorrente das interações "sociocomunicativas" historicamente constituídas (TOMASELLO, 2003, p.131), nenhum mundo é edificado do nada. $\mathrm{O}$ mundo, como o edificamos, deriva de mundos que estão disponíveis para nós. São deles, conforme Goodman, que extraímos o mundo que construímos.

Não há, portanto, como não aceitar que a construção e a reconstrução cotidiana de mundos têm estreita relação com as tecnologias da informação e com os conteúdos midiáticos. Nas relações com as mídias e com as tecnologias de informação mundos são cotidianamente construídos e reconstruídos a partir de versões criadas pelos atores 


\section{míDiA eCOti DiAno}

midiáticos. E para evitar um questionamento moralista sobre o caráter persuasivo e sedutor dos meios, seus efeitos sobre os jovens, e a pretensa omissão de educadores e pais, a questão que deve ser colocada não é, por exemplo, a semelhança verificada entre a violência contida nos programas midiáticos e a violência encontrada na realidade dos jovens. A questão, ao modo de Benjamin (2004), está nos processos que engendram tais semelhanças. Quando o jovem está diante de uma vastidão de informações ele realiza escolhas, as quais ele julga ter relação com os mundos que habita. Voltando a Goodman (1995, p.52), é comum no cotidiano e amplamente confirmado pelos laboratórios de psicologia: "Que encontramos o que estamos preparados para encontrar", ou seja, é tanto o que se procura como aquilo que "afronta" as "expectativas".

Os modos de fazer mundos de Goodman, com a ressalva do autor de que não são os únicos, tampouco precisos ou imperativos, são construídos com a "composição e decomposição", por meio da "enfatização", com o uso de sistemas de "ordenação", por meio da "supressão e complementação" e pela "deformação". Com essas ferramentas intelectuais combinatórias são estabelecidas as verdades no interior do mundo em que foram gestadas. Para Bruner (1997), a validade deste modo de pensar, qual seja, de que não há apenas um mundo, mas inúmeros deles construídos com recursos simbólicos, está na radicalidade da reflexão. Por essa via são aceitas tanto "as realidades criadas pela história de ficção, assim como aquelas criadas pela ciência" (BRUNER, 1997, p.111).

\section{Jovens Construtores de Mundos}

De fato, a realidade apreendida pelos jovens não está apenas no noticiário. Está também nas histórias de ficção. E uma história de ficção é tão capaz de espelhar a realidade quanto um noticiário. Assim são as telenovelas para os estudantes que trabalham: "mostram a vida como ela é". As telenovelas, as minisséries, são programas estruturados a partir de uma narrativa ficcional, mas feitos sob medida para o imaginário 


\section{míDiA eCOti DiAno}

do seu público-alvo: a realidade ganha forma nos diálogos dos personagens, nos enredos interpretados. Os programas jovens nas TVs, como Malhação, por exemplo, segundo os alunos das quatro escolas, dizem o que eles devem saber da vida. Ocorre que a vida vivida não é igual para os quatro grupos. Os alunos e alunas das quatro escolas, como já dito, têm origens em grupos sociais distintos, vivem circunstâncias completamente distintas com suas famílias e nas escolas que estudam. Apesar das distâncias que os separam, dos grupos que os caracterizam e das lacunas culturais e econômicas que os diferenciam, eles são recorrentes quando elegem seus atores mediáticos.

Os depoimentos recorrentes nas quatro escolas demonstram como certos programas retratam "os problemas da vida", como drogas, sexo etc. Por mostrar os problemas dos jovens, o programa Malhação ajuda o aluno a formar a sua opinião. Ocorre que quando há excessiva repetição das mesmas versões, a reconstrução que se processa imediatamente após a desconstrução do discurso original se ergue a partir das pilastras fornecidas pelos discursos repetitivos. Como estes se apresentam como portadores da verdade, da face real do que é a realidade, suas pilastras são também aquelas sob as quais os jovens das quatro escolas erguem as suas versões de mundo. Entretanto, no debate sobre os problemas e o modo de vida em "Malhação", um jovem, aluno da escola frequentada por estudantes que trabalham, trouxe uma voz dissonante e conduziu seus colegas a uma outra reconstrução, divergente da versão que ganhava unanimidade. Ele disse: "não concordo com vocês. Na Malhação ninguém trabalha, ninguém carrega "marmita" $"$. Aquilo não é minha vida". Por este exemplo, os mundos são construídos e desconstruídos no processo dialético.

Para os alunos e alunas das quatro escolas, as mídias são portadoras da realidade. São suficientemente capazes de espelhar exatamente como é o mundo, como é o cotidiano. Os jovens compreendem e aceitam que aquilo que vêem, escutam e lêem é aquilo que

\footnotetext{
11 Almoço pronto que trabalhadores levam de suas casas quando não dispõem de recursos para o pagamento de restaurantes, ou mesmo quando o empregador não disponibiliza vale refeição.
} 


\section{míDiA eCOti DiAno}

\section{PPGMC}

realmente aconteceu. E o que aconteceu, e foi mostrado, converteu-se em realidade. Para o grupo de jovens que persegue uma vaga na universidade pública, o que é veiculado, especialmente na televisão, é o que eles precisam ver e saber para melhor compreender o mundo e explicá-lo. Já os estudantes que trabalham encaram as mídias com certo temor, um receio de que as situações mostradas, principalmente nos programas policiais, aconteçam com eles. Para os trabalhadores que estudam, o noticiário mostra o que está acontecendo no mundo e com as pessoas que lhe são familiares, ao mesmo tempo em que os ensina como viver em segurança. Já no outro extremo, no grupo que vai estar sob quaisquer circunstâncias na universidade, as notícias alertam e ensinam como ele deve agir para não ser o alvo da violência.

A importância do sistema mediático para os jovens não está apenas em sua capacidade de mostrar o que aconteceu, mas, também, de gerar o que será, para nós, convertido em realidade. Há, até, uma inversão: para os estudantes que trabalham, "a nossa vida roda, gira, assim, ao redor da mídia”. Para esta reflexão, Lippmann (1972, p.151) contribui com uma provocante assertiva: "Na maior parte das vezes, não vemos primeiro para depois definir, mas primeiro definimos e depois vemos". Em suma, controladores e propagadores de conteúdos midiáticos disponibilizam à audiência universos simbólicos. Já o jovem (e também todos nós), ao receber algo elaborado, vai recompor ou decompor, vai deformar ou complementar, vai enfatizar e ordenar, como pode até suprimir, mas, acima de tudo, fará isso, em um primeiro momento, a partir dos universos simbólicos encontrados nos ambientes midiáticos que frequenta.

Os jovens com os quais conversei referem-se aos aparelhos midiáticos como sendo "meu rádio", "meu computador", “minha televisão". Já os programas radiofônicos, televisivos, ou sites na Internet, têm a "minha cara", dizem eles. Em resumo, o conteúdo midiático se aloja e se torna parte do próprio cotidiano. Por essa mediação fluem também as relações nas quais são construídos conhecimentos e estereótipos, por onde 


\section{míDiA eCOti DiAno}

\section{PPGMC}

emaranhados de interesses, crenças, conceitos e pré-conceitos se expandem, se entrelaçam e exigem, segundo Moises, Geraldi e Collares (2002, p.103) respostas imediatas. Entre as muitas possíveis, estão a necessidade de diálogos mais frequentes das instituições de ensino, mídias e pais sobre os mundos que os jovens constroem.

O ponto crucial para se aceitar a idéia de que o jovem, e não somente ele, constrói sua realidade com o suporte dos meios tecnológicos e informativos é que a realidade, lembram Berger e Luckmann (2002), é tanto aquilo que se admite que seja como a própria análise que se faz dela. É a interpretação com a coerência que dá sentido. Uma coerência que se manifesta na organização dos textos de jornais, de revistas e sites noticiosos, nas imagens que dão veracidade ao que se fala: que reafirma que aquilo que se vê é, de fato, o que o outro também viu. O cotidiano dos jovens, no qual as mídias ocupam espaços de destaque, é o tempo presente e a confirmação da existência do jovem nele. "É no cotidiano que se tem prazer ou se sofre. Aqui e agora", diz Lefebvre (1991, p.27).

A questão, considerando a condição do jovem, é que as realidades velozmente construídas, como são as oferecidas pelas mídias, exigem igual velocidade e competência para realizar escolhas. Com isso, diante não só da velocidade, mas, principalmente, da quantidade de conteúdo disponibilizado, relacionar no cotidiano o texto com contexto exige fé e confiança: "esses dois sentimentos 'ocupam mais espaços' na cotidianidade, que sua função mediadora torna-se necessária em maior número de situações" (HELLER, 2000, p.33). À impossibilidade de controlar e dominar o que o rodeia no cotidiano, a confiança transforma-se no mecanismo que torna possível a interação com os sistemas mediáticos, no entendimento de Giddens (2002, p.11): “a confiança é um meio de interação com sistemas abstratos que esvaziam a vida cotidiana de seu conteúdo tradicional, ao mesmo tempo em que constroem influências 


\section{míDiA eCOti DiAno}

globalizantes. A confiança gera aquele 'salto de fé' que o envolvimento prático demanda".

No universo das tecnologias de informação, uma das questões centrais está no poder de controlar os fluxos (CASTELLS, 2001). Essa é uma tarefa que a sociedade delega e legitima aos centros produtores de informação, não apenas àqueles tradicionalmente assim reconhecidos, como agências de notícias, emissoras de televisão, emissoras de rádios, jornais e revistas. Há novos controladores de fluxos informacionais jornalísticos alojados em conexões frequentemente utilizadas pelos jovens, como, por exemplo, a página personalizada do Google, a página principal do MSN Messager, do Yahoo, as redes sociais, nos games, entre outros. Os próprios jovens, em suas redes, são também controladores de fluxos informativos. Essa crescente tendência, Castells (2001) a explica a partir da evolução histórica e da transformação tecnológica, o que torna a informação noticiosa parte de um modelo cultural como base para a organização social e para a interação entre as pessoas. A notícia é um fator de equilíbrio e de estabilidade, à medida que há uma relação entre o que as mídias publicam e o que a população julga importante (TUCHMAN, 1983, p.14).

Os mundos são construídos pelos emissores quando eles realizam escolhas, quando compõem, conforme a exigência técnica do meio utilizado, um roteiro que tenha como proposta mostrar um acontecimento ou uma ficção. O receptor, independente do grupo social, também escolhe, decompõe o composto, reconstrói o que estava construído e o faz dando ênfase conforme o seu critério de ordenamento de importância. Os estudantes que trabalham assistem ao noticiário policial e este tema é recorrente entre eles, pois temem que um dia sua família possa ser atacada, ainda que residam em locais onde a violência urbana não é recorrente. E isso ocorre, segundo eles, porque o mundo é assim mesmo. Já entre os trabalhadores que estudam, este tipo de programa tem uma função pedagógica, pois além de ensinar como viver em segurança, aponta para quem é quem 


\section{míDiA eCOti DiAno}

no seu mundo social. Para os alunos e alunas do grupo que tem como certa sua ida a uma universidade, o noticiário policial mostra o que de fato pode acontecer a eles, se não estudarem em escolas com segurança, se não forem levados pelos pais até a porta da escola.

Ao priorizar os programas e as leituras, sejam quais forem, o jovem aluno, ou aluna, está elegendo o que ele, ou ela, julga ser mais importante para o seu atual momento da vida: "Pessoal, assim, tipo, a gente. Eu acho que é assim: de um modo geral a gente vai se interessar por uma coisa que está na nossa realidade", diz Selma, do grupo de alunos que deseja alcançar a universidade. $\mathrm{O}$ ato de priorizar exclui o não priorizado. Edificase, nesse procedimento, uma versão de mundo cujo suporte está nas pilastras sustentadas pela correspondência entre o discurso midiático e a experiência cotidiana.

O modelo de apresentação das informações, em forma ficcional ou de noticiário, faz o jovem se sentir momentaneamente desarmado, dado o modo irresistível de como o conteúdo é apresentado. Os alunos e alunas sentem certa voracidade, às vezes incontrolável, por alguns determinados temas. É como se não pudessem ficar sem tomar conhecimento de um assunto, nunca alcançável. As falas sugerem certa vulnerabilidade, como a existência de algo que aciona o prazer, no dizer de Kátia, do grupo de estudantes que trabalham. Jurema, do grupo que luta para estar em uma universidade, acredita na existência de um processo que atua em seu cérebro, deixando-o momentaneamente sem ação, como se fosse uma pessoa viciada.

A presença do ator midiático no cotidiano do jovem é tão intensa que não basta acompanhá-lo em seu programa. Torna-se necessário acompanhar também a vida dele fora da ficção ou da televisão, uma tarefa a que muitas publicações, sites e até outros programas televisivos se dedicam. Mas o interesse pela vida de pessoas midiáticas extrapola a publicação especializada neste tema. A variedade de temas produzida por 


\section{míDiA eCOti DiAno}

uma publicação de interesse geral, inclusive sobre a vida dos famosos, leva o jovem a ocupar o seu tempo com este tipo de leitura, em detrimento de outras: "Assim, quando eu pego a Veja, ai tem aquela parte sintetizada, do que o fulano disse. Adoro ler aquilo. Não sei porque. Sabe, assim, eu acho ruim isso. Ai que tá, a coisa que eu não acho boa da mídia, sabe. Te prende, é uma coisa que você não tem explicação, assim”, diz a Jurema do grupo que deseja chegar a uma universidade. Do mesmo grupo de Jurema, Carmem complementa: "Ela mistura muito. (...) você quer ler mais notícias mesmo sobre economia, política, não sei o que, você vai folheando assim, você vê a cara da Xuxa. Você vai parar ali e vai começar a ler. Ai, na hora que você terminou de ler o negocinho da Xuxa, você ficou cansado e não vai ler mais o resto".

Os mundos construídos e reconstruídos podem conter maior ou menor grau de complexidade. A diretora da escola onde estão matriculados os estudantes que trabalham não compreende como um tema policial pode ocupar tanto tempo nas conversas de seus alunos. Para o coordenador da escola do grupo de trabalhadores que estudam, o noticiário policial e o cotidiano dos alunos e alunas são vizinhos um do outro. Para a diretora da escola do grupo de alunos que tem a universidade como um caminho certo, há um mundo perigoso fora da proteção da família e da escola, enquanto extensão da residência e da herança cultural familiar. Heloisa, dessa escola, por exemplo, disse: “... eu nunca andei na rua sozinha...”. Mas, é no grupo de estudantes que trabalham que surgiu a reconstrução de uma versão que requer especial atenção. Moradora em uma região que em nada lembra os tiroteios, as balas pedidas, os assaltos e assassinatos, as sirenes de viaturas policiais ligadas das grandes cidades, Maria faz do tema violência uma obsessão. Acredita que qualquer pessoa pode ser a próxima vítima. Para ela, o noticiário policial presta um serviço. Diz a aluna: "É só a gente ler para ver que isso, que, pode acontecer. Por exemplo: se minha mãe morre e eu não estava com ela, eu fico sabendo o que aconteceu. A gente tem que saber onde a gente está vivendo, porque se não tivesse a notícia, como que a gente ia saber...”. 


\section{míDiA eCOti DiAno}

\section{Considerações Finais}

As mídias tem presença marcante na vida dos jovens das quatro escolas. No caso da jovem Maria, que frequenta a escola do grupo de estudantes que trabalham, o conteúdo midiático é capaz de levá-la a recriar um universo que efetivamente está longe do lugar onde ela mora. No entanto, a questão aqui colocada está menos neste resultado e mais no processo que se forma e atua no contexto onde ela vive. Os assuntos policiais aparecem para este grupo como o tema preferido. A prioridade desta escola é dar competência para o aluno prestar concurso público e alcançar uma universidade. Para os alunos, isso se dá na perspectiva de trabalhar durante o dia e estudar à noite. Os atores dos programas preferidos, policiais ou marginais, são tratados pelos alunos, segundo a diretora, como heróis. Neste grupo, no entendimento da diretora, os pais não comparecem à escola e não cobram resultados.

O problema do não comparecimento dos pais é mais grave na escola frequentada por trabalhadores que estudam. A família, além de ausente, é como se não existisse: o aluno está por sua própria conta, admite o diretor. Os programas policiais são também os mais assistidos e a escola, antes de ser um espaço de aprendizagem, é um campo de violências: plantas são pisoteadas, paredes são pichadas e colegas e professores desrespeitados. Para o diretor desta escola, a prioridade é a pedagogia da disciplina. $\mathrm{O}$ horizonte de expectativas profissionais se resume às atividades oferecidas no próprio bairro. E os alunos tratam o acesso às universidades não como uma oportunidade, mas como algo inalcançável. Com isso, este assunto raramente está em pauta no seu cotidiano.

Os pais, em sua maioria, também não estão presentes na escola do grupo de alunos que desejam alcançar uma universidade pública. Os que comparecem são os pais de alunos mais bem sucedidos na escola. Porém, segundo a diretora, os pais protegem tanto seus filhos que tentam intervir nos procedimentos pedagógicos, especialmente se estes 


\section{míDiA eCOti DiAno}

\section{PPGMC}

procedimentos prejudicam as notas. Cita como exemplo pais que levam filhos para passear em período de aulas e depois querem da escola revisão de notas, caso os alunos tenham perdido atividades avaliativas. Quanto às mídias, telenovelas, telejornais, emissoras de rádio e revistas nacionais, principalmente, são os programas e meios mais buscados por este grupo. Quanto aos temas midiáticos recorrentes nas conversas entre as alunas, segundo a diretora, figuram principalmente a moda, o corpo, a estética, economia e política. Estes dois últimos, porque são temas presentes em todo vestibular. Entre os alunos, os temas de conversas estão relacionados com esportes e também com economia e política.

Como nos três grupos anteriores, os pais dos alunos que estarão sobre quaisquer circunstâncias na universidade não comparecem na escola, mas entregam seus filhos na porta e não querem uma escola aberta, mas instituições que protejam os seus filhos. É o medo, diz a diretora, medo da violência, por isso mantém seus filhos isolados. O objetivo principal da escola e formar alunos para atender as necessidades da sociedade. Serão os futuros executivos de empresas e gestores do país. Para uma das professoras com experiência também em outra escola, o professor é geralmente visto como um profissional de segunda classe. Para ela, a valorização do professor tem relação com o lugar onde ele atua. As mídias também tem presença marcante na vida deste grupo. Usuários de TVs por assinatura e Internet, viajam muito, inclusive para outros países.

Como apresentado, nos quatro grupos é recorrente a ausência dos pais nas escolas, assim como o diálogo com os filhos, segundo os diretores, coordenadores e professores ouvidos. No entanto, o acervo de conhecimento "à mão" é diferente nos quatro grupos, como também são distintos os contextos culturais, econômicos e sociais. Os jovens parecem estar mais por conta das interlocuções com os atores midiáticos e colegas do grupo. Assim, se a comunicação de fato ocorre no campo da recepção, isso não se dá de forma verticalizada, dos meios para os seus públicos. Diante da infinidade de opções 


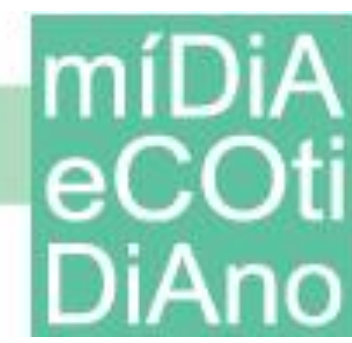

midiáticas, os quatro grupos buscam os conteúdos mais próximos de suas vidas. Aceitam que estes conteúdos se alojem em seus cotidianos, por sua vez convertidos cada um, a seu modo, em mundos midiáticos. Discutir como são reconstruídos, compostos, decompostos, enfatizados e ordenados, suprimidos, complementados ou deformados, segundo as ferramentas de Goodman (1995), constituem tanto uma tarefa dos próprios meios, como da escola, dos pais e dos próprios jovens.

\section{Referências Bibliográficas}

ADORNO, Theodor Wiesengrund. A Atualidade da Filosofia. In: Educação On Line. http://www.educacaoonline.pro.br/index.php?option=com_content\&view=article\&id=1 75:a-atualidade-da-filosofia\&catid=11: sociologia $\&$ Itemid=22, 2003. Último acesso em 30 de maio de 2012.

BAKHTIN, Mikhail. Estética da Criação Verbal. São Paulo: Martins Fontes, 2003.

BAKHTIN, Mikhail. (Volochinov) Marxismo e Filosofia da Linguagem. São Paulo: Hucitec, 2004.

BAUDELAIRE, Charles. Sobre a Modernidade. $4^{\circ}$ ed. Rio de Janeiro: Paz e Terra, 1996.

BENJAMIN, Walter. Obras Escolhidas I: Magia e Técnica, Arte e Política, v. $1.7^{\circ}$ ed. São Paulo: Brasiliense, 2004.

BERGER, Peter L. e LUCKMANN, Thomas. A Construção Social da Realidade: Tratado de Sociologia do Conhecimento. 21. ed. Trad: Floriano de Souza Fernandes. Petrópolis: Vozes, 2002.

BRUNER, Jerome. Realidade Mental, Mundos Possíveis. Porto Alegre: Artes Médicas, 1997.

CAPALBO, Creusa. Metodologia das Ciencias Sociais: a fenomenologia de Alfred Schütz. $2^{\circ}$ ed. Londrina: Editora UEL, 1998.

CASTELlS, Manuel. A Sociedade em Rede. A era da informação: economia, sociedade e cultura, v. 1, $5^{\circ}$ ed. São Paulo: Paz e Terra, 2001. 


\section{PPGMC}

DiAno

CERTEAU, Michel de. A Invenção do Cotidiano: 1. Artes de Fazer. Petrópolis: Vozes, 1994.

FREIRE, Paulo. A Importância do Ato de Ler: em três artigos que se completam. $43^{\circ}$ ed. São Paulo: Cortez, 2002.

GALEANO, Eduardo. Livro dos Abraços. Porto Alegre: LPM, 1995.

GIDDENS, Antony. Modernidade e Identidade. Trad: Plinio Dentzien. Rio de Janeiro: Jorge Zahar, 2002.

GONZÁLEZ REY, Fernando Luiz. Sujeito e Subjetividade: uma aproximação histórico-cultural. Trad: Raquel Souza Lobo Guzzo. São Paulo: Pioneira Thomson, 2003.

GOODMAN. Nelson. Modos de Fazer Mundos. Trad. Antonio Duarte. Porto: Edições Asa, 1995.

HELlER, Agnes. O Cotidiano e a História. $6^{\circ}$ ed. Trad. Carlos Nelson Coutinho e Leandro Konder. São Paulo: Paz e Terra, 2000.

HUSSERL, Edmund. Conferências de Paris. Lisboa: Edições 70, 1992.

HUSSERL, Edmund. Idéias para uma Fenomenologia Pura e para uma Filosofia Fenomenológica. Aparecida: Idéias \& Letras, 2006.

LEFEBVRE, Henry. A Vida Cotidiana no Mundo Moderno. Trad: Alcides Joao de Barros. São Paulo: Ática, 1991.

LIPPMANN, Walter. Estereótipos. In: STEINBERG, Charles. (Org.) Meios de Comunicação de Massa. São Paulo: Cultrix, 1972, p. 149-159

MOISES, Maria Aparecida Afonso; GERALDI, João Wanderley; COLLARES, Cecilia Azevedo Lima. As aventuras do Conhecer: da transmissão à interlocução. Revista Eletrônica: Educação \& Sociedade, ano XXIII, n. 78, abril de 2002, p.91-116. Texto Disponível no seguinte endereço: http://www.scielo.br/pdf/es/v23n78/a07v2378.pdf. Último acesso: 30 de janeiro de 2012.

MEDINA, Cremilda. Notícia, um Produto à Venda: jornalismo na sociedade urbana e industrial. $2^{\circ}$ ed. São Paulo: Summus, 1988. 


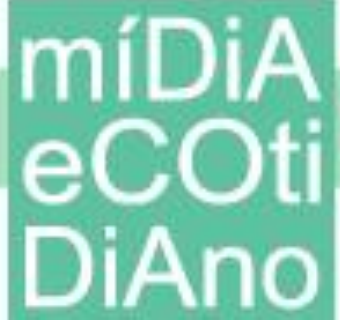

SCHÜTZ, Alfred e LUCKMANN, Thomas. Strukturen der Lebenswelt. Neuwied: Luchterhand, 1975.

SCHÜTZ; Alfred. El Problema de la Realidad Social. Buenos Aires: Amorrortur, 2003.

TOMASELLO, Michael. Origens Culturais da aquisição do conhecimento humano. São Paulo: Editora Martins Fontes, 2003

TUCHMAN, Gaye. La Producción de la Noticia: estudio sobre la construcción de la realidad. Barcelona: Editorial Gustavo Gili, 1983. 